\title{
Pedagogical Strategies Used to Enact Formative Assessment in Science Classrooms:
}

\section{Physical Sciences Teachers' Perspectives}

\author{
Halalisani Mngomezulu ${ }^{1}$, Sam Ramaila ${ }^{1} \&$ Thasmai Dhurumraj $^{1}$ \\ ${ }^{1}$ Department of Science and Technology Education, Faculty of Education, University of Johannesburg, South Africa \\ Correspondence: Sam Ramaila, Department of Science and Technology Education, Faculty of Education, University \\ of Johannesburg, South Africa.
}

Received: November 9, 2021

Accepted: February 11, 2022

Online Published: February 14, 2022

doi:10.5430/ijhe.v11n3p158

URL: https://doi.org/10.5430/ijhe.v11n3p158

\begin{abstract}
The importance of the enactment of formative assessment as a pedagogical tool in science teaching and learning cannot be over-emphasized. Teachers encounter pedagogical challenges when enacting formative assessment in science classrooms. These pedagogical challenges underscore the need to explore teachers' perspectives on pedagogical strategies used to enact formative assessment in science classrooms. This study examined grade 10 Physical Sciences teachers' perspectives on pedagogical strategies they adopted to enact formative assessment in science classrooms in diverse schools in South Africa. The empirical investigation invoked the sociocultural theory as a conceptual lens to provide insightful elucidation into the nature of teachers' perspectives on pedagogical strategies used to enact formative assessment in science classrooms. A generic qualitative research approach was employed. Data were collected through semi-structured focus group interviews and classroom observations. The study involved 12 purposively selected grade 10 Physical Sciences teachers as participants. The findings revealed that grade 10 Physical Sciences teachers adopted various pedagogical strategies when enacting formative assessment in science classrooms. However, meaningful enactment of formative assessment in science classrooms was largely hampered by a myriad of contextual factors such as class size and general lack of essential resources. It is recommended that teacher professional development interventions coordinated by the Department of Basic Education ought to make provision for meaningful opportunities to enhance teacher professional capacity required for coherent enactment of formative assessment as an essential tenet in science education. Theoretical implications for pedagogic innovation are discussed.
\end{abstract}

Keywords: formative assessment, pedagogical strategies, classroom practice, perspectives

\section{Introduction}

The enactment of formative assessment is central to learners' academic achievement in various educational settings. The enactment of formative assessment requires teachers to effectively and appropriately implement relevant pedagogical strategies as part of their classroom practice. Elwood (2006) asserts that formative assessment is central to the improvement of the quality of learning in schools. In support of this assertion, Black and Wiliam (2011) indicate that formative assessment can occur at all stages of the teaching and learning process with the teacher using evidence as part of ongoing instruction to support teaching and learning. Effective enhancement of learners' conceptual understanding requires teachers to adopt various formative assessment strategies to identify learners' needs and make appropriate adjustments to teaching and learning (Centre for Educational Research and Innovation, 2005). This paper explores South African Physical Sciences teachers' perspectives on pedagogical strategies used to enact formative assessment as a pedagogical tool in science classrooms to enhance learners' scientific literacy.

Teachers' perspectives on formative assessment strategies within the scientific context have received considerable attention in in an effort to improve teachers' classroom practices (Frapwell, 2010). Policymakers and education officials in the education fraternity have developed and recommended different formative assessment strategies to support teachers and learners in implementing formative assessment in the classrooms (Yan et al., 2021). These formative assessment strategies include the use of questioning, feedback, peer assessment, concept-cartoons as well as formative use of summative assessment. The impact of the afore-mentioned formative assessment strategies in enhancing learners' conceptual understanding has been noted. Research indicates that the impact of formative 
assessment strategies in science classrooms is relatively limited due to different challenges science teachers encounter such as class size, lack of physical and material resources, accessibility and suitability of learner-teacher support materials, the language of teaching and learning as well as parental involvement (Black \& Wiliam, 1998; Black \& Wiliam, 2011).

In addition, Morgan and Hansen (2007) assert that teachers find certain formative assessment strategies difficult to employ in their classroom practices, thus making them feel less competent and creating uncertainty in their practice. The prevalence of these challenges resulted in some formative assessment strategies in science classrooms being avoided by teachers. Teachers use formative assessment strategies that work better for them, neglecting the primary objectives of meeting learners' needs (Morgan \& Hansen, 2007). According to Ni Chroinin and Cosgrave (2013), teachers need extensive support and guidance to determine the effectiveness of the use of different strategies in science education. Furthermore, Locke and Graber (2008) posit that Physical Sciences teachers prefer to embrace those strategies that are easier and most familiar to them rather than exploring a variety of strategies. Plant (2007) concurs with Locke and Graber (2008) that many teachers get assessment 'horribly wrong' in science education as they merely focus only on summative assessment, which occurs towards the end of the unit of the work which solely focuses on learners' ability to perfect and memorize concepts they have learnt for the purpose of grading. Johnson (2008) highlighted the difficulties Physical Sciences teachers encounter when making subjective judgments relating to learners' effort in science lessons. These difficulties include inadequate use of formative assessment strategies reflecting very little about the actual learners' learning and misconceptions associated with scientific concepts.

In South African schools, Physical Sciences is taught by teachers who received training in either Bachelor of Education or Post Graduate Certificate in Education programs. Formative assessment strategies are addressed within these programs in an effort to train pre-service teachers accordingly (Yan et al., 2021). Despite this effort, there is little evidence to suggest that formative assessment strategies are effectively integrated into science teaching and learning in schools. The pursuit of this study is predicated on the need for an effective and meaningful enactment of formative assessment in science classrooms. It is against this background that the study explored grade 10 Physical Sciences teachers' perspectives on pedagogical strategies used to enact formative assessment in science classrooms. The empirical investigation was guided by the following research question.

What are grade 10 Physical Sciences teachers' perspectives on pedagogical strategies used to enact formative assessment in science classrooms?

\section{Literature Review}

South African curriculum reforms have been characterized by major changes in assessment practices (Department of Basic Education, 2011). The relationship between teachers' views on the nature of pedagogical strategies adopted in Physical Sciences teaching and learning and the nature of assessment practices teachers adopt to assess learners requires formal empirical inquiry. This formal empirical inquiry is necessary because the alignment between the two key aspects may influence science classroom practice. A research study conducted by Nasri et al. (2011) demonstrated that teachers have a generally positive perception about formative assessment as they believe that such an assessment practice helps teachers to inculcate critical and creative skills in science classrooms in particular. However, teachers felt that formative assessment increases the amount of administrative work as the feedback has to be provided to each learner at regular intervals.

There are some promising formative assessment strategies recommended for enhancing learners' conceptual understanding. These formative assessment strategies include questioning, feedback, concept-cartoons, peer assessment and formative use of summative assessment (Schiemer, 2000). However, science teachers still struggle to effectively and meaningfully embed formative assessment in their classroom practice. Bottage et al. (2007) contend that problem-based learning strategies are effective in teaching and learning as they can improve understanding and reduce achievement gaps in learners' learning when appropriately integrated while implementing formative assessment. Similarly, Black and Wiliam (2011) highlighted the importance of effective questioning by the teacher in supporting the enactment of formative assessment. The Curriculum and Assessment Policy Statement (CAPS) indicates that teachers must create a classroom environment where interaction will be used to effectively embed the pedagogical intentions to develop learners' understanding to pave the way for the use of formative assessment strategies to promote classroom interaction (Department of Basic Education, 2011).

Al-Zahrani and Al-Bargi (2017) state that classroom interaction is far more than learners' ability to speak and express themselves. They further assert that classroom interaction comprises many types of classroom participation occurrences such as small group discussions, peer assessment and provision of feedback. Walsh (2013) describes formative assessment strategies in classroom practice as a kind of communication that requires the collective 
competencies of all parties concerned. A research study conducted by Walsh (2013) revealed that formative assessment strategies used by science teachers are not effective in enhancing learners' interaction if the display questions are just merely based on recall and remembering of facts and are not in the form of analytical questions. Albergaria-Almeida (2010) concurs by stating that teachers' questions often prevent learners from expressing their own views and ideas, thus suppressing learners' scientific and conceptual understanding. This implies that embedding formative assessment using one strategy does not necessarily lead to higher participation or more classroom interaction. Furthermore, it is important for science teachers to recognize the correlation between learners' proficiency level and the formative assessment strategy to be adopted. For instance, when a science teacher adopts the questioning strategy when enacting formative assessment, the questions posed must challenge learners to think critically at a cognitive level that they have not yet attained for classroom interaction to occur effectively.

Despite the documented pedagogical affordances of formative assessment strategies, teachers face a myriad of instructional challenges when enacting formative assessment in science classrooms. These instructional challenges include classroom size, lack of physical and material resources, accessibility and suitability of learner-teacher support materials, language of learning and teaching, as well as parental involvement (Black \& Wiliam, 1998; Black $\&$ Wiliam, 2011). Nakabugo (2008) asserts that when enacting formative assessment in large classes, teachers tend to provide fewer activities and exercises to reduce their marking load at the expense of sustainable use of appropriate pedagogical strategies. When embedding formative assessment in classroom practice in large classes, there is a limited space to move around and conduct small group discussions that could enhance learners' effective coverage of content (Nakubugo, 2008).

Bound and Falchivok (2006) state that the purpose of formative assessment is to facilitate learning and provision of information to enable learners to be more effective and close the existing gap in their learning. Science teachers show limited and less able to use different strategies and tools when embedding formative assessment particularly when classroom lesson objectives are not clearly articulated in the teaching process (Bound \& Falchivok, 2006). Despite the implementation of strategic interventions by the Department of Basic Education, science teachers in rural areas are resource-constrained, both physical and material. According to Owoko (2010), the term resource does not refer only to teaching materials but also to the time available for instruction, the knowledge and skills teachers acquired in tertiary education and the experience they possess. Physical and material resources include peripatetic services, support staff, community involvement, laboratories, and chemicals (Oyugi \& Nyaga, 2010). The inadequacy of these resources acts as an obstacle to the meaningful enhancement of learners' understanding of scientific concepts through the enactment of formative assessment in science classrooms.

At another pragmatic level, Okongo et al. (2015) recommend that adequate teaching and learning resources should be provided to teachers to ensure effective implementation of formative assessment and more funds should be allocated for accessing and procuring physical and material resources to make meaningful enactment of formative assessment feasible. Yet another challenge in the use of formative assessment strategies lies in the language of learning. For instance, Yore and Treagust (2006) identified three language challenges, namely, home language, instructional language and science language. Learners come to school with their home language and teachers have to provide appropriate scaffolding to move them from home language to instructional and science language and this poses a significant challenge to science teachers. Hodgen and Wiliam (2006) suggest that science teachers need to be competent and patient with learners and try to connect what science learners learn in the classroom and what they already know to demystify the notion that science is a hard subject. Lastly, parental involvement is another challenge facing science teachers when embedding formative assessment in classroom practice. Ntekane (2018) points out that parents from rural areas often fail to create strong bonds with the school thereby making science teaching much more difficult and challenging as some parents are unable to read and write and can only communicate in their home language with the result that they cannot be actively involved in formative assessment activities such as homework and assignments. Chin (2006) argues that there is a need for science teachers to be effectively supported, guided and professionally developed on the use of formative assessment strategies in order to scaffold learners' thinking to construct scientific knowledge. Moreover, science teachers should be guided and supported to make relevant connections between formative assessment strategies and the desired learning goals in science teaching and learning.

\section{Conceptual Framework}

The study is underpinned by the sociocultural theory as the underlying conceptual framework. The Zone of Proximal Development (ZPD) is a key construct in Lev Vygotsky's theory of learning and development. Zone of Proximal Development is defined by Vygotsky (1978) as "the distance between the actual developmental level as determined by independent problem solving and the level of potential development as determined through problem-solving 
under adult guidance, or in collaboration with more capable peers" (p. 86). In terms of the sociocultural theory, human learning is viewed as a social process and the origination of human intelligence in society. Vygotsky (1978) believes that humans use tools from society and culture which include speech and writing to mediate their social environment. The sociocultural theory is predicated on the notion that a learners or child can perform different tasks through guidance from adults accomplished in the Zone of Proximal Development (ZPD). The ZPD is the stage in which the adult guides and provides assistance to the child towards the accomplishment of the task, with the adult acting as a More Knowledgeable Other (MKO). The teachers' role in ZPD is to mediate learning such that learners gain the independence to perform certain tasks on their own. The Zone of Proximal Development is illustrated in figure 1 below.

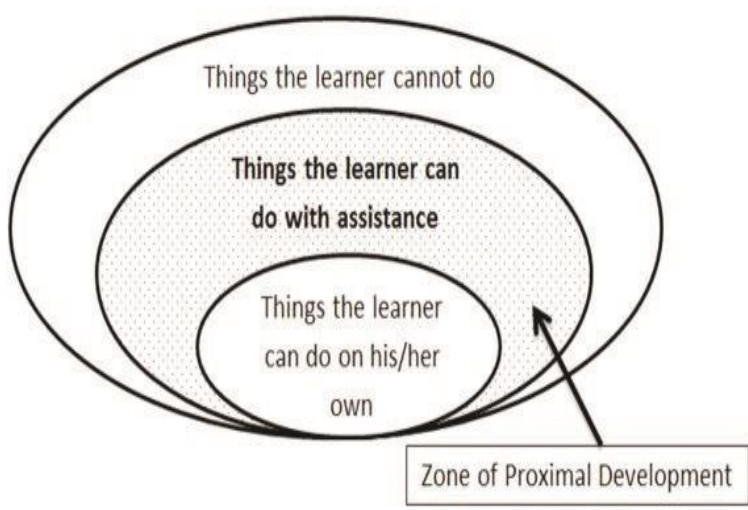

Figure 1. Zone of Proximal Development (Vygotsky, 1978)

The rationale for adopting this theory is that it enables teachers and learners to realize their defined roles during the implementation of formative assessment in the classroom. In support of this notion, Leahy and Lyon (2005) maintain that assessment is not unidirectional but rather involves teachers and learners through activities that enhance teaching and learning. Duran (2010) emphasized that the provision of scaffolding which includes feedback and self-regulation plays a pivotal role in enhancing learners' understanding. This study sought to explore how Physical Science teachers embed formative assessment in their classroom practice. To this end, the sociocultural perspective served as a conceptual lens to provide insightful elucidation into the modalities adopted by Grade 10 Physical Science teachers when embedding formative assessment in their classroom practice. By its very nature, the sociocultural theory postulates that teachers provide feedback to learners through formative assessment in order to adjust the ongoing teaching and learning with a view to improving learners' achievement of intended instructional goals. The adoption of the sociocultural theory enabled the researchers to trace the extent to which learning is recognized within a social perspective through interaction with others.

\section{Research Methodology}

\section{Research design}

The study adopted a generic qualitative research design. McMillan and Schumacher (2010) posit that a qualitative study is meant to be descriptive and interpretive in nature. The qualitative design provided opportunities for meaningful exploration of grade 10 Physical Sciences teachers' perspectives on pedagogical strategies used to enact formative assessment in science classrooms.

\section{Participants, sampling and setting}

The target population were grade 10 Physical Sciences teachers. A purposive sampling procedure was employed. According to Kumar (2019), purposive sampling allows the researcher to choose participants on the basis of extensive knowledge about the event or episode being studied and it offers opportunities for in-depth analysis. The empirical investigation involved 12 grade 10 Physical Sciences teachers from diverse schools in the KwaZulu-Natal Province of South Africa. The schools were largely under-resourced and were in quintile 1,2 and 3. The teachers were all involved in the teaching of Physical Sciences in the Further Education and Training phase (FET). The participants were all in a better position to provide valuable, reliable and insightful information about pedagogical strategies they use when embedding formative assessment in their classroom practice.

\section{Data collection and analysis}

Semi-structured focus group interviews and classroom observations were used to collect data. Three groups of 
teachers were interviewed. The first and second groups consisted of 5 teachers while the third group only had two teachers. The interviews for each group of teachers took one hour. The semi-structured focus group interviews provided both the researcher and participants the relaxation and flexibility to answer and probe questions of interest freely in their own words. In a semi-structured focus group interview, the researcher can make follow up questions on interesting points or avenues while the process is in progress (De Vos et al., 2011). Prior to the commencement of the interviews, all participants were made aware that recording devices would be used to record the proceedings. During interviews, participants were requested to provide their views on pedagogical strategies used to enact formative assessment in science classrooms as well as the challenges encountered when embedding formative assessment in their classroom practice. Collected data were transcribed verbatim and the emerging themes were generated from participants' narratives. Classroom observations were conducted in 12 schools. One grade 10 Physical Sciences lesson per school was observed with the aim of exploring how science teachers embed formative assessment in their classroom practice. Kumar (2019) indicates that this data collection method is used if a researcher seeks to understand the phenomenon in a social setting while remaining separate on the activities being studied.

\section{Ethical considerations}

Permission to conduct research at schools was obtained from the KwaZulu-Natal Provincial Department of Education. The nature of the research was described to the participants through full disclosure and participation was voluntary. Anonymity and confidentiality were ensured at all times. Participants were informed of any conflict of interest and potential harm for purposes of obtaining informed consent. In addition, participants were allowed to withdraw their participation at any stage without any consequences.

\section{Findings and Discussions}

The study involved purposively selected grade 10 Physical Sciences teachers. The demographic profile of the participants is provided in Table 1 below.

Table 1. Demographic profile of the participants

\begin{tabular}{cclcl}
\hline Participant & Qualification & Gender & School Quintile & Teaching experience \\
& & & 1 & 2 Years \\
1 & Bed & Female & 2 & 3 Years \\
2 & Bed & Male & 3 & 4 Years \\
3 & HDE & Female & 1 & 6 Years \\
4 & BA & Female & 2 & 5 Years \\
5 & BA & Female & 3 & 5 Years \\
6 & BSc & Male & 1 & 4 Years \\
7 & Bed & Female & 1 & 3 Years \\
8 & HDE & Female & 2 & 4 Years \\
9 & Bed & Male & 1 & 7 Years \\
10 & Bed & Male & 2 & 6 Years \\
11 & HDE & Male & 3 & 7 Years \\
12 & Bed & Male & & \\
& & & &
\end{tabular}

Key findings were clustered according to the themes that emerged during data analysis, namely: pedagogical strategies adopted by Physical Sciences teachers when enacting formative assessment in science classrooms, challenges encountered by Physical Sciences teachers when enacting formative assessment in science classrooms, Physical Sciences teachers' professional development needs for an effective and meaningful enactment of formative assessment in science classrooms.

Theme 1: Pedagogical strategies adopted by Physical Sciences teachers when enacting formative assessment in science classrooms

The Physical Sciences teachers adopted various pedagogical strategies when enacting formative assessment in 
science classrooms. They further stated that these pedagogical strategies have to be sustained by virtue of their relevance to the creation of conducive classroom environments. The pedagogical strategies adopted were largely perceived to be responsive to the diverse needs of learners. Small group discussions and peer assessment were used by the teachers when enacting formative assessment in science classrooms as they were perceived to foster a sense of independence and self-esteem among the learners. This sentiment is encapsulated in the following excerpt.

I use small group discussions, I group learners, and give them work to do in collaboratively, then I attend those groups to explain further and this strategy is useful when you want learners to lead learning and become independent. I use peer assessment as it makes learners to work with their peers, peer assessment enables learners to explain different aspects to each other because some learners understand better if they work with their peers (P1).

The teachers indicated that the use of small group discussions and peer assessment provided opportunities for embracing learner-centred approaches, which promoted active learner engagement. Concept-mapping was used to explain the relationship between ideas, concepts, principles, laws and theories. The teachers indicated that the use of concept maps helped learners to acquire deeper conceptual understanding through the provision of opportunities for learners to visualize the relationship between complex scientific concepts by systematically organizing them. This observation is reflected in the following excerpt.

When I am integrating formative assessment, I use mind maps or concept maps as they enable learners to see the integration of the certain aspects pertaining to the concept presented to them (P2).

Naylor and Keogh (2013) emphasize that the use of concept maps motivate learners to actively construct and master correct scientific concepts as they are exposed to how concepts are related to each other. Other pedagogical strategies that were used by the teachers include discovery learning, cooperative learning, problem-based learning, differentiated instruction and inquiry-based learning.

\section{Theme 2: Challenges encountered by Physical Sciences teachers when enacting formative assessment in science classrooms}

The Physical Sciences teachers encountered a myriad of instructional challenges when enacting formative assessment in science classrooms. These instructional challenges include large class size, general lack of essential resources, suitability of learner-teacher support materials as well as lack of parental involvement and support. Despite numerous efforts aimed at addressing challenges afflicting meaningful enactment of formative assessment in teaching and learning, these challenges continue to persist (Ogunkola, 2011).

\section{Class size}

The teachers indicated that large class size hinders meaningful enactment of formative assessment in science classrooms. This sentiment is captured in the following excerpt.

Due to overcrowding, I am unable to move around to check my learners' progress as a result I am failing to give individual attention and control. Science requires practicals and experiments to be conducted regularly but I cannot administered and conduct those assessments due to large class size, and that limits learners understanding about how certain reactions and demonstrations occurs (P3).

Large class size made it increasingly difficult for the teachers to provide individualized attention to the learners, as the following excerpt illustrates.

Due to classroom overcrowding, I am not able to provide individual attention especially to the learners that are struggling with science so I end up using questioning and feedback strategy addressing the whole class (P4).

The provision of quality education is predicated on the development of higher-order cognitive skills through the adoption of appropriate innovative pedagogical strategies. For instance, the use of questioning as a formative assessment strategy improves higher-order thinking and not just a mere recall or remembering of facts (Myhill \& Dunkin, 2007). These sentiments are reflected in the following excerpt.

Providing feedback to my learners work better for me, after I gave them class activities, I make sure that we do corrections on the chalkboard as a feedback mechanism, and learners mark their work using a pencil and ask for clarity if it is necessary (P5).

Busch (2016) cautions that feedback must be orderly and must be provided regularly to address learners' loops encountered in daily lessons. Similarly, Florez and Sammons (2013) maintain that feedback ought to be informative 
and descriptive for it to be meaningful to learners.

\section{Lack of resources}

According to Physical Sciences Curriculum and Assessment Policy Statement Grade 10-12 (Department of Basic Education, 2011), every science teacher must have material resources to perform certain experiments to ensure the effective teaching and learning of science in the form of hands-on activities. However, the Physical Sciences teachers indicated that effective and meaningful enactment of formative assessment in science classrooms is hampered by a general lack of resources. This sentiment is encapsulated in the following excerpt.

I teach Physical Sciences using only textbook because in my school we do have adequate resources such as chemicals, apparatus and experiments kits, it is therefore difficult to teach science in theory even if it needs to be practical (P6).

The teachers further indicated that the learner-teacher support material provided by the Department of Basic Education is not ideally suited for an effective and meaningful enactment of formative assessment in science classrooms.

\section{Theme 3: Physical Sciences teachers' professional development needs for effective and meaningful enactment of formative assessment in science classrooms}

Effective and meaningful enactment of formative assessment in science classrooms requires teacher professional competence in the use of appropriate pedagogical strategies. The Physical Sciences teachers highlighted professional developments needs that must be addressed by the Department of Basic Education to build teacher professional capacity required for an effective and meaningful enactment of formative assessment in science classrooms. The highlighted professional developments needs include the provision of appropriate training on the enactment of formative assessment in science classrooms, provision of opportunities for demystifying the use of inquiry-based learning, provision of appropriate training on the integration of improvised resources in science teaching and learning and provision of meaningful opportunities for embracing technology-enhanced learning. The teachers bemoaned the structure and purpose of professional development interventions implemented by the Department of Basic Education, as the following excerpt demonstrates.

The department organizes workshops and cluster meetings mainly on summative assessment and analysis of Grade 12 results each and every term. Although we attend professional teacher development programmes, these programmes last less than an hour and do not consider teachers' professional needs (P7).

These observations are consistent with the view of Ajani (2018) who indicated that some professional development programmes have challenges that militate against the purpose of effectiveness of teachers.

\section{Interpretation of key findings in terms of the adopted conceptual framework}

The sociocultural perspective provided insightful elucidation into the modalities adopted by grade 10 Physical Sciences teachers when embedding formative assessment in their classroom practice. While Physical Sciences teachers demonstrated a positive disposition about the pedagogical affordances of formative assessment as an innovative pedagogical tool to foster meaningful teaching and to learn in science classrooms, coherent enactment for formative assessment is bedevilled by critical factors such as large class size and general lack of instructional resources. General lack of resources appeared to have an adverse impact on the provision of appropriate scaffolding. The sociocultural theory postulates that teachers provide feedback to learners through formative assessment in order to adjust the ongoing teaching and learning with a view to improving learners' achievement of intended instructional goals. Yet, contextual factors such as large class size had an adverse impact on the provision of constructive feedback to learners as well as the coherent development of learners' self-regulation skills. In addition, a myriad of contextual factors identified made it increasingly difficult for teachers and learners to realize their defined roles during the implementation of formative assessment in the classroom. Leahy and Lyon (2005) maintain that assessment is not unidirectional but rather involves teachers and learners through activities that enhance teaching and learning. The realization of this key strategic imperative was largely hampered by inadequate teacher professional competence in enacting formative assessment in science classrooms.

\section{Recommendations arising from the study}

The Department of Basic Education faces the key imperative to provide meaningful platforms for Physical Sciences teachers to fully embrace pedagogic innovation for the coherent realization of effective enactment of formative assessment in science classrooms. Meaningful enactment of formative assessment remains a key strategic imperative within the broader South African context. The provision of quality education hinges to a large degree on the 
provision of essential resources. Professional development interventions coordinated by the Department of Basic Education ought to make provision for appropriate training on the enactment of formative assessment in science classrooms. South African higher education institutions and other key stakeholders with vested interest in education ought to provide meaningful platforms for coherent and sustainable enhancement of teacher professional capacity to harness pedagogical affordances of formative assessment with a view to develop scientific literacy in its broadest sense in science classrooms. In addition, these interventions ought to provide opportunities for demystifying the use of inquiry-based learning, provision of appropriate training on the integration of improvised resources in science teaching and learning and provision of meaningful opportunities for embracing technology-enhanced learning.

\section{Conclusion}

Effective and meaningful enactment of formative assessment in science classrooms remains a daunting pedagogical challenge for Physical Sciences teachers. Effective and meaningful enactment of formative assessment in science classrooms is hampered by a myriad of context-specific factors. There is a need for the provision of meaningful platforms that foster pedagogic innovation required to strengthen teacher professional practice in its broadest with a view to achieving holistic professional development of Physical Sciences teachers. Schools ought to be adequately resourced to enable teachers to meaningfully enact formative assessment to ensure coherent development of scientific literacy in its broadest sense in science classrooms. Significant investment in the provision of resources can serve to pave the way for improved academic achievement in Physical Sciences in particular.

\section{References}

Ajani, O. A. (2018). Influence of teachers' professional development on classroom practices in South Africa and Nigeria. Journal of Alternative Perspectives in the Social Sciences, 9(2), 156-170.

Albergaria-Almeida, P. (2010). Classroom questioning: teachers' perceptions and practices. Procedia-Social and Behavioral Sciences, 2(2), 305-309. https://doi.org/10.1016/j.sbspro.2010.03.015

Al-Zahrani, M. Y., \& Al-Bargi, A. (2017). The impact of teacher questioning on creating interaction in EFL: A discourse analysis. Canadian Center of Science and Education, 10(6), 135. https://doi.org/10.5539/elt.v10n6p135

Black, P., \& Wiliam, D. (1998). Assessment and classroom learning. Assessment in Education, 5(1), 7-74. https://doi.org/10.1080/0969595980050102

Black, P., \& Wiliam, D. (2011). What is assessment for learning? Studies in Educational Evaluation, 37(1), 3-144. https://doi.org/10.1016/j.stueduc.2011.03.001

Bottage, B. A., Rueda, E., Serlin, R. C., Hug, Y., \& Kwon, J. M. (2007). Shrinking achievement differences with anchored math problem: Challenges and Possibilities. The Journal of Special Education, 41(1), 31-49. https://doi.org/10.1177/00224669070410010301

Bound, D., \& Falchikov, N. (2006). Aligning assessment with long-term learning. Assessment \& Evaluation in Higher Education, 31(4), 399-413. https://doi.org/10.1177/00224669070410010301

Busch, B. (2016). Seven ways to give better feedback to your learners, published by the newspaper 'The Guardian' in 10 November 2016.

Centre for Educational Research and Innovation (CERI). (2005). Formative assessment: Improving learning in secondary classroom. Paris: OECD.

Chin, C. (2006). Classroom interaction in science: teacher questioning and feedback to students' responses. International Journal of Science Education, 28(11), 1315-1346. https://doi.org/10.1080/09500690600621100

Department of Basic Education (2011). Curriculum and Assessment Policy Statement: Grade 10-12 Physical Sciences. Pretoria, South Africa.

De Vos, A. S., Strydom, H., Fouche, C. B., \& Delport, C. S. L. (2011). Research at grass roots for the Social Sciences and Human service professions. Van Schaik Publishers.

Duran, R. P. (2010). Assessing English language learner's achievement. Review of Research in Education, 32(1), 292-327. https://doi.org/10.3102/0091732X07309372

Elwood, J. (2006). Formative assessment: Possibilities, boundaries and limitations. Assessment in Education: Principles, Policy \& Practice, 13(2), 215-232. https://doi.org/10.1080/09695940600708653

Florez, M. T., \& Sammons, P. (2013). Assessment for learning: effect and impact. Oxford University Department of 
Education.

Frapwell, A. (2010). Assessment in Physical Education-Fit for purpose? We've got an APP for that! Physical Education Matters, 5(3), 8-13.

Hodgen, J., \& Wiliam, D. (2006). Mathematics inside the Black Box: Assessment for Learning in the Mathematics Classroom.

Johnson, R. (2008). Overcoming resistance to achievement-based unit grading in Secondary physical education. Journal of Physical Education Recreation and Dance, 79(4), 1-60. https://doi.org/10.1080/07303084.2008.10598164

Kumar, R. (2019). Research Methodology: A Step by Step Guide for Beginners. London: SAGE Publications.

Leahy, S., \& Lyon, C. (2005). Classroom Assessment: Minute by Minute, Day by Day in classrooms that use assessment to support learning, teachers continually adapt instruction to meet student needs. Educational Leadership: Journal of the Department of Supervision and Curriculum Development, N.E.A, 63(3), 19-24.

Locke, L., \& Graber, K. (2008). Elementary school Physical Education: Expectations and Possibilities. The Elementary School Journal, 108(3), 365-372. https://doi.org/10.1086/529108

McMillan, J., \& Schumacher, S. (2010). Research in Education: Evidence-Based Inquiry, $7^{\text {th }}$ Edition.

Morgan, P., \& Hansen, V. (2007). Recommendations to improve primary school physical education: Classroom teachers' perspectives. Journal of Educational Research, 101(2), 99-111. https://doi.org/10.3200/JOER.101.2.99-112

Myhill, D., \& Dunkin, F. (2007). Questioning Learning. Ore Open Research Exeter. University of Exeter.

Nakubugo, M. G. (2008). Universal Primary Education for Equal Growth? The paradox of large classes in Uganda. Journal of International Cooperation in Education, 11(1). Makerere University, Kampala.

Nasri, N., Roslan, S. N., Sekuan, M. I., Bakar, K. A., \& Puteh, S. N. (2010). Teachers' perception on alternative assessment. Procedia-Social and Behavioral $\quad$ Sciences, $\quad 7(\mathrm{C}), \quad 37-42$. https://doi.org/10.1016/j.sbspro.2010.10.006

Naylor, S., \& Keogh, B. (2013). Concepts cartoons: what have we learnt? Journal of Turkish Science Education, $10(1), 3-11$

Ni Chroinin, D., \& Cosgrave, C. (2013). Implementing formative assessment in primary physical education: Teachers' perspectives and experiences. Physical Education and Sport Pedagogy, 18(2), 219-233. https://doi.org/10.1080/17408989.2012.666787

Ntekane, A. (2018). Parental Involvement in Education. North West University. Doi: 10.13140/RG.2.2.3633021440.

Ogunkola, B. J. (2011). Science teachers' and students perceived difficult topics in the integrated science curriculum of lower secondary schools in Barbados. World Journal of Education, 1(2), $17-29$. https://doi.org/10.5430/wje.v1n2p17

Okongo, R. B., Ngao, G., Rop, N. K., \& Nyongesa, W. J. (2015). Effect of availability of teaching and learning resources on the implementation of Inclusive Education in Pre-school centres in Nyamira North. Sub-Country, Kenya. Journal of Education and Practice, 6(35).

Owoko, I. S. (2010). The Role of Advocacy in Enhancing Equalization of Opportunities for Disabled People. (Unpublished paper) presented in Leonard Cheshire Disability workshop in Kisumu.

Oyugi, N. L., \& Nyaga, M. M. (2010). Introduction to Contemporary Issues Affecting Education. Kenya Institute of Special Needs.

Plant, I. (2007). The complex nature of assessment. Physical Education Matters, 2(2), 26-27.

Vygotsky, L. S. (1978). Interaction between learning and development. In M. Cole, V. John-Steiner, S. Scribner, \& E. Souberman (Eds.), Mind in Society: The Development of Higher Psychological Processes (pp. 79-91). Cambridge, MA: Harvard University Press.

Walsh, S. (2013). Classroom discourse and teacher development. Edinburgh University press.

Yan, Z., Xiao, Y., Sin, K., Yang, L., \& Guo, W. (2021). Formative assessment practices in special school classrooms with the support of E-Books: A case study. Frontiers in Education, 6, Article 674869. https://doi.org/10.3389/feduc.2021.674869 
Yore, L., \& Treagust, D. (2006). Current realities and future possibilities: Language and science literacy-empowering research and informing instruction. International Journal of Science Education, 28(2/3), 291-314. https://doi.org/10.1080/09500690500336973

\section{Copyrights}

Copyright for this article is retained by the author(s), with first publication rights granted to the journal.

This is an open-access article distributed under the terms and conditions of the Creative Commons Attribution license (http://creativecommons.org/licenses/by/4.0/). 